\title{
Supporting Information - Experimental assessment of the practical oxidative stability of lithium thiophosphate solid electrolytes
}

Georg F. Dewald ${ }^{\mathrm{a}, \mathrm{b}}$, Saneyuki Ohno ${ }^{\mathrm{a}, \mathrm{b}}$, Marvin A. Kraft ${ }^{\mathrm{a}, \mathrm{b}}$, Raimund Koerver ${ }^{\mathrm{a}, \mathrm{b}}$, Paul Tilla,b Nella M. Vargas-Barbosa ${ }^{\mathrm{c}}$, Jürgen Janek ${ }^{\mathrm{a}, \mathrm{b}^{*}}$, Wolfgang G. Zeier ${ }^{\mathrm{a}, \mathrm{b}^{*}}$

${ }^{a}$ Institute of Physical Chemistry, Justus-Liebig-University Giessen, Heinrich-Buff-Ring 17, D-35392 Giessen, Germany.

${ }^{b}$ Center for Materials Research (LaMa), Justus-Liebig-University Giessen, Heinrich-BuffRing 16, D-35392 Giessen, Germany.

${ }^{c}$ Max Planck Institute for Solid State Research, Heisenbergstrasse 1, 70569 Stuttgart Germany 


\section{Characterization of solid electrolytes}

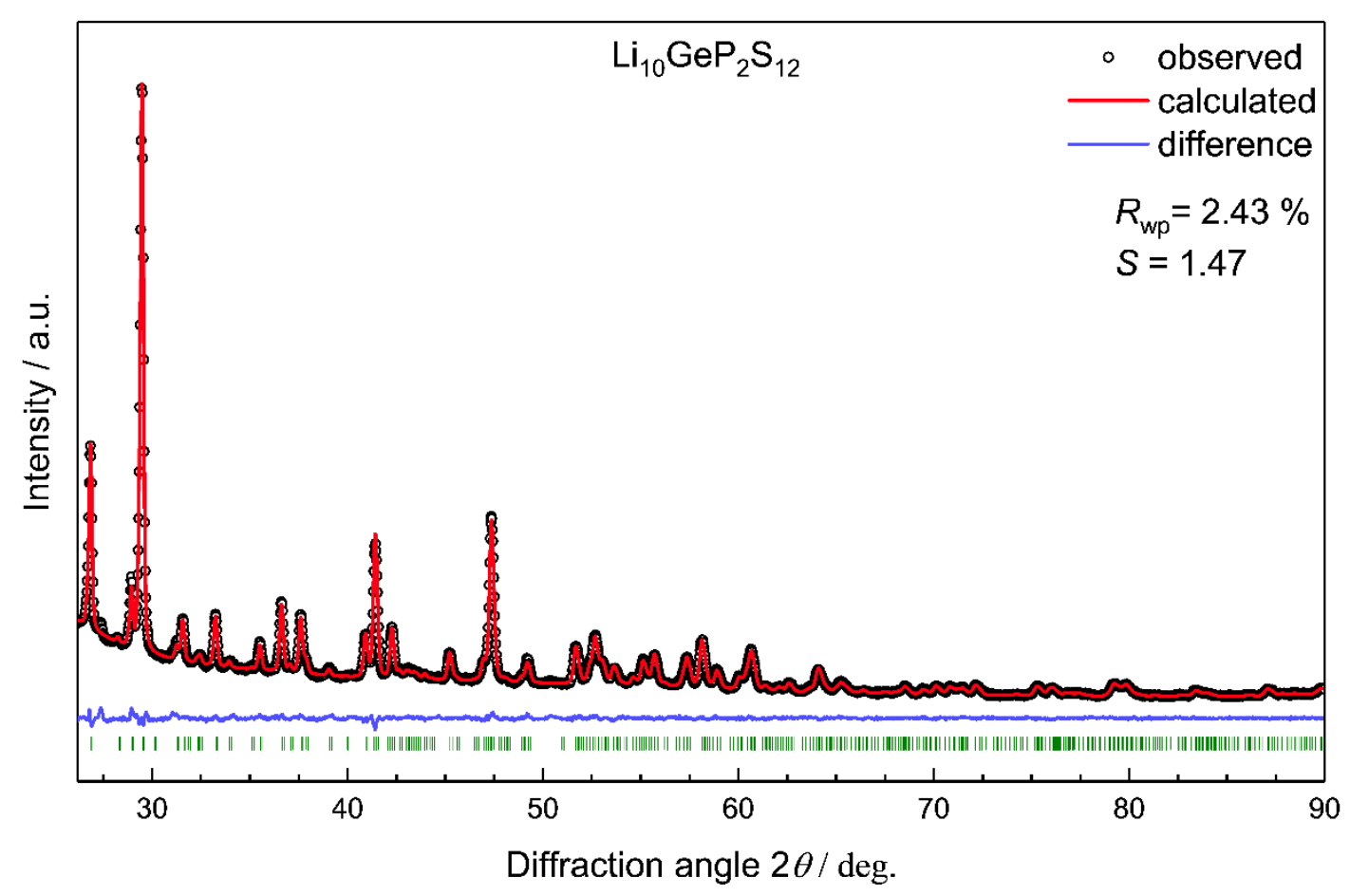

Figure S 1: X-ray powder diffraction data and results of Rietveld refinement of $\mathrm{Li}_{10} \mathrm{GeP}_{2} \mathrm{~S}_{12}$. Calculated positions of the Bragg reflections are shown as vertical ticks.

Table S 1: Refined structural parameters for $\mathrm{Li}_{10} \mathrm{GeP}_{2} \mathrm{~S}_{12}$ obtained from Rietveld refinement of $X R D$ data between $26-90^{\circ} 2 \theta$. The space group is P42/nmc (No. 137). Obtained lattice parameters are $a=8.7068(1) \AA, c=12.6079(3) \AA$, which is in good agreement with reported values. ${ }^{S 1}$ Values in parentheses represent statistical errors on the last significant digit. Fit residuals $\left(R_{p}, R_{w p}, R_{\exp }, S\right): 1.88 \%, 2.43 \%, 1.66 \%, 1.47$.

\begin{tabular}{ccccccc}
\hline atom & Wyckoff & \multicolumn{3}{c}{ atomic coordinates } & \multirow{2}{*}{ occ. } & $\boldsymbol{B}_{\text {iso }} / \AA^{\mathbf{2}}$ \\
\cline { 3 - 5 } & site & $x$ & $y$ & $z$ & & \\
\hline Li1 & $16 h$ & 0.498 & 0.013 & 0.449 & 0.50 & 7 \\
\hline $\mathbf{L i 2}$ & $8 g$ & 0.25 & 0.226 & 0.195 & 0.54 & 7 \\
\hline $\mathbf{L i 3}$ & $8 f$ & 0.496 & -0.004 & 0.25 & 0.62 & 7 \\
\hline $\mathbf{L i 4}$ & $4 c$ & 0.25 & 0.75 & 0.499 & 0.68 & 7 \\
\hline P1 & $4 d$ & 0.25 & 0.25 & $0.9421(2)$ & 0.5 & $2.70(5)$ \\
\hline Ge1 & $4 d$ & 0.25 & 0.25 & $0.9421(2)$ & 0.5 & $2.70(5)$ \\
\hline P2 & $2 b$ & 0.25 & 0.25 & 0.75 & 1 & $2.7(1)$ \\
\hline S1 & $8 g$ & 0.25 & $0.9374(3)$ & $0.6592(2)$ & 1 & $4.41(7)$ \\
\hline S2 & $8 g$ & 0.25 & $0.0461(2)$ & $0.3464(2)$ & 1 & $3.32(6)$ \\
\hline S3 & $8 g$ & 0.25 & $0.4483(2)$ & $0.0431(2)$ & 1 & $2.93(6)$ \\
\hline
\end{tabular}




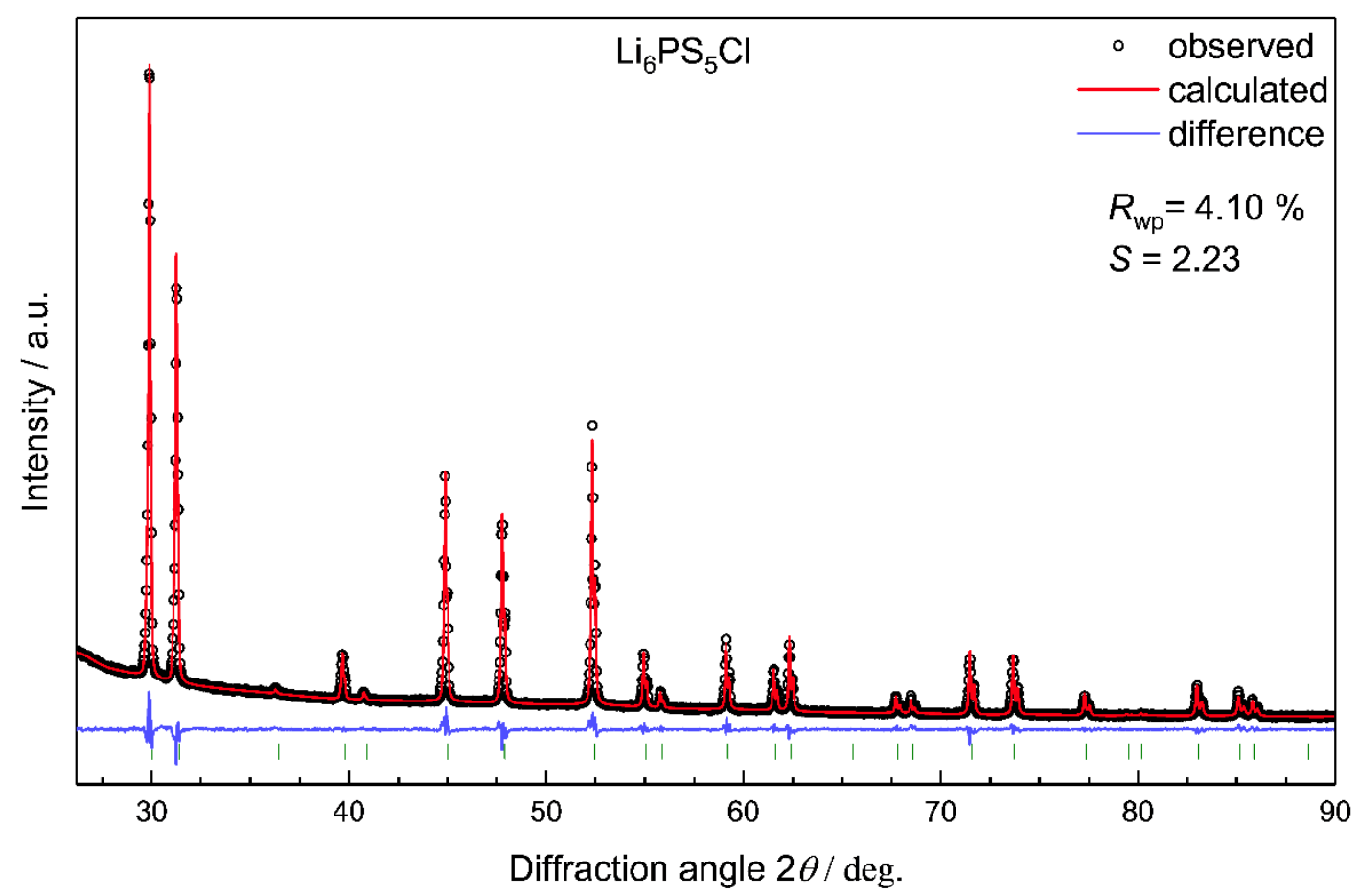

Figure S 2: X-ray powder diffraction data and results of Rietveld refinement of $\mathrm{Li}_{6} \mathrm{PS}_{5} \mathrm{Cl}$. Calculated positions of the Bragg reflections are shown as vertical ticks.

Table S 2: Refined structural parameters for $\mathrm{Li}_{6} \mathrm{PS}_{5} \mathrm{Cl}$ obtained from Rietveld refinement of XRD data between $26-90^{\circ} 2 \theta$. The space group is $F-43 m$ (No. 216). Obtained lattice parameter is $a=9.85485(7) \AA$. Values in parentheses represent statistical errors on the last significant digit. Fit residuals $\left(R_{p}, R_{w p}, R_{\text {exp }}, S\right): 2.83 \%, 4.10 \%, 1.83 \%, 2.23$. All lithium parameters as well as occupation parameters for chlorine and sulfur positions were fixed to neutron data as published by Kraft et al. The herein refined lattice parameter is consistent with the published value. ${ }^{S 2}$

\begin{tabular}{ccccccc}
\hline atom & Wyckoff & \multicolumn{3}{c}{ atomic coordinates } & \multirow{2}{*}{ occ. } & \multirow{2}{*}{$\boldsymbol{B}_{\text {iso }} / \AA^{\mathbf{2}}$} \\
\cline { 3 - 5 } & site & $x$ & $y$ & $z$ & & \\
\hline Li1 & $48 h$ & 0.3202 & 0.0183 & 0.6798 & 0.5 & 5.5 \\
\hline Cl1 & $4 a$ & 0 & 0 & 1 & 0.385 & $3.94(9)$ \\
\hline C12 & $4 d$ & 0.25 & 0.25 & 0.75 & 0.615 & $2.96(8)$ \\
\hline P1 & $4 b$ & 0 & 0 & 0.5 & 1 & $2.49(3)$ \\
\hline S1 & $4 d$ & 0.25 & 0.25 & 0.75 & 0.385 & $2.96(8)$ \\
\hline S2 & $16 e$ & $0.1200(2)$ & $-0.1200(2)$ & $0.6200(2)$ & 1 & $4.48(5)$ \\
\hline S3 & $4 a$ & 0 & 0 & 1 & 0.615 & $3.94(9)$ \\
\hline
\end{tabular}




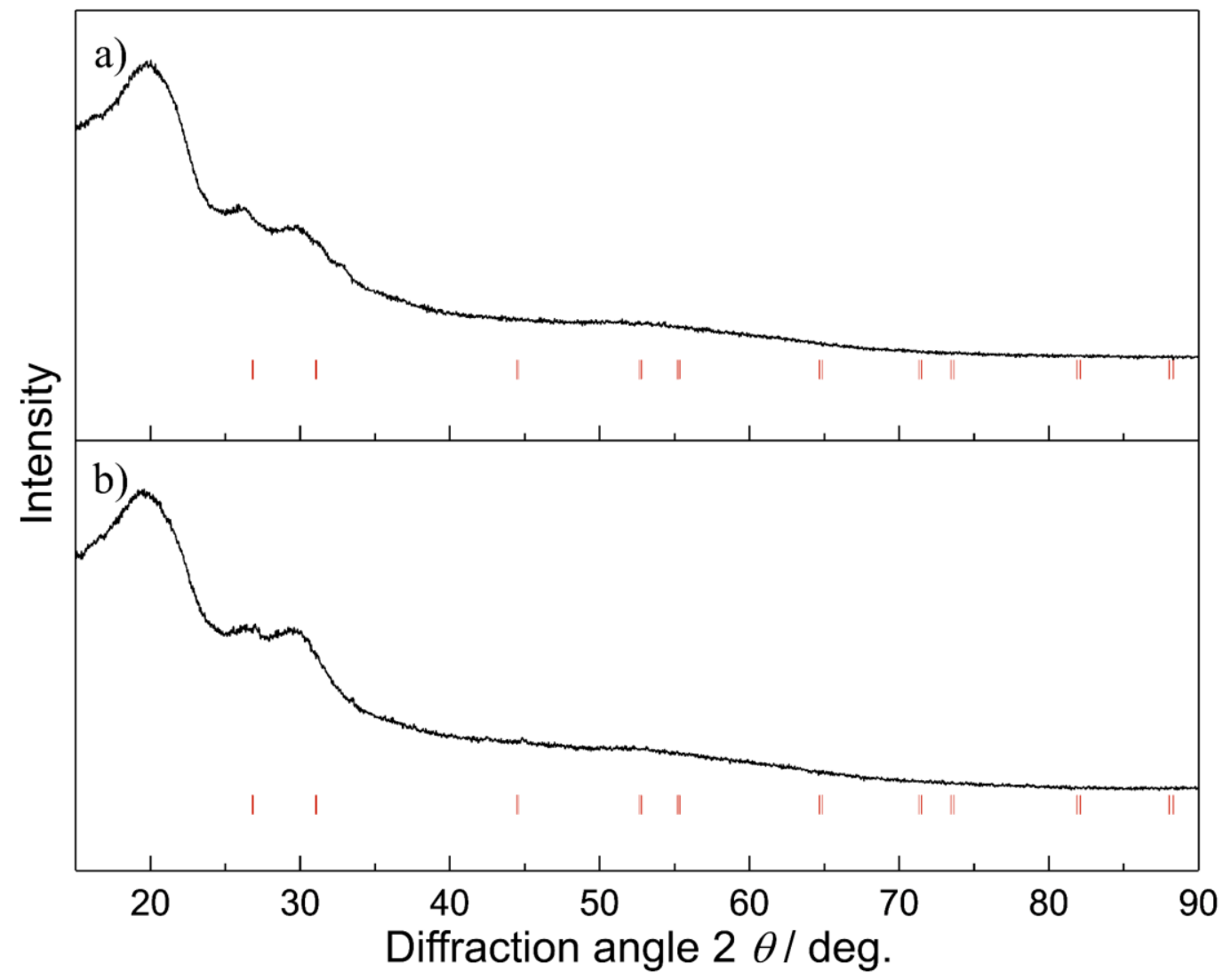

Figure S 3: X-ray powder diffraction data for 70:30 Li $\mathrm{i}_{2} \mathrm{~S}-\mathrm{P}_{2} \mathrm{~S}_{5}$ glass (a) and 75:25 $\mathrm{Li}_{2} \mathrm{~S}-\mathrm{P}_{2} \mathrm{~S}_{5}(\mathrm{~b})$. The employed polyimide foil is contributing to the diffuse background and only minor reflections of starting material $\mathrm{Li}_{2} \mathrm{~S}$ (red ticks) were found. 

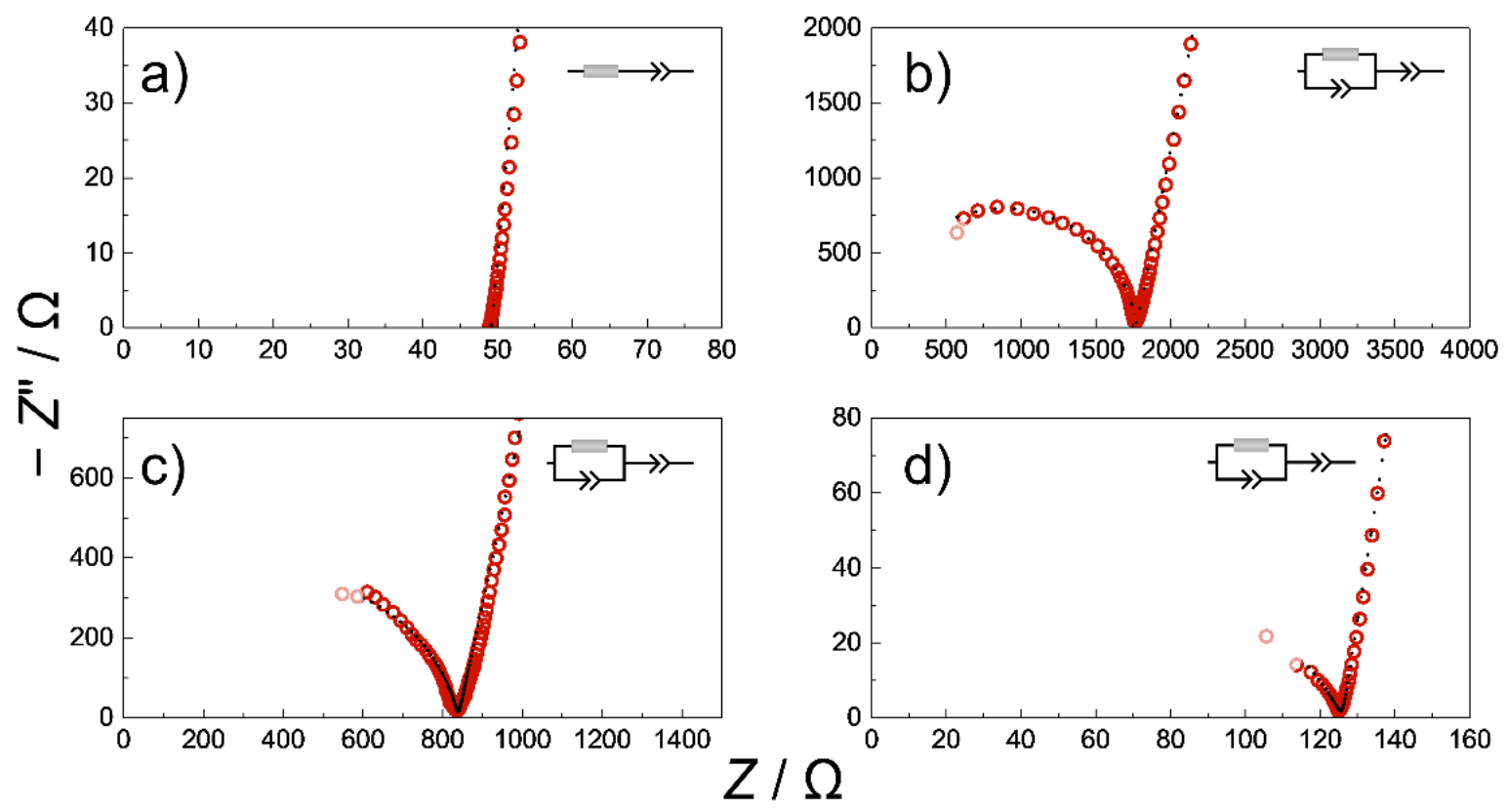

Figure S 4: EIS data of $\mathrm{Li}_{10} \mathrm{GeP}_{2} \mathrm{~S}_{12}(\mathrm{a}), 70: 30 \mathrm{Li}_{2} \mathrm{~S}_{-} \mathrm{P}_{2} \mathrm{~S}_{5}$ glass (b), 75:25 Li $\mathrm{i}_{2} \mathrm{~S}_{2} \mathrm{P}_{5}$ glass (c) and $\mathrm{Li}_{6} \mathrm{PS}_{5} \mathrm{Cl}(\mathrm{c})$ recorded at room temperature with an amplitude of $10 \mathrm{mV}$ for a frequency range of $7 \mathrm{MHz}-100 \mathrm{mHz}$ in Nyquist representation. Based on the sample dimensions, conductivities are determined to be $6.5 \mathrm{mS} \cdot \mathrm{cm}^{-1}, 0.2 \mathrm{mS} \cdot \mathrm{cm}^{-1}, 0.7 \mathrm{mS} \cdot \mathrm{cm}^{-1}$ and $2.3 \mathrm{mS} \cdot \mathrm{cm}^{-1}$, respectively. Due to the fast conducting $\mathrm{Li}_{10} \mathrm{GeP}_{2} \mathrm{~S}_{12}$, only blocking behavior of the electrodes was resolved for this sample. 


\section{Cyclic voltammetry}
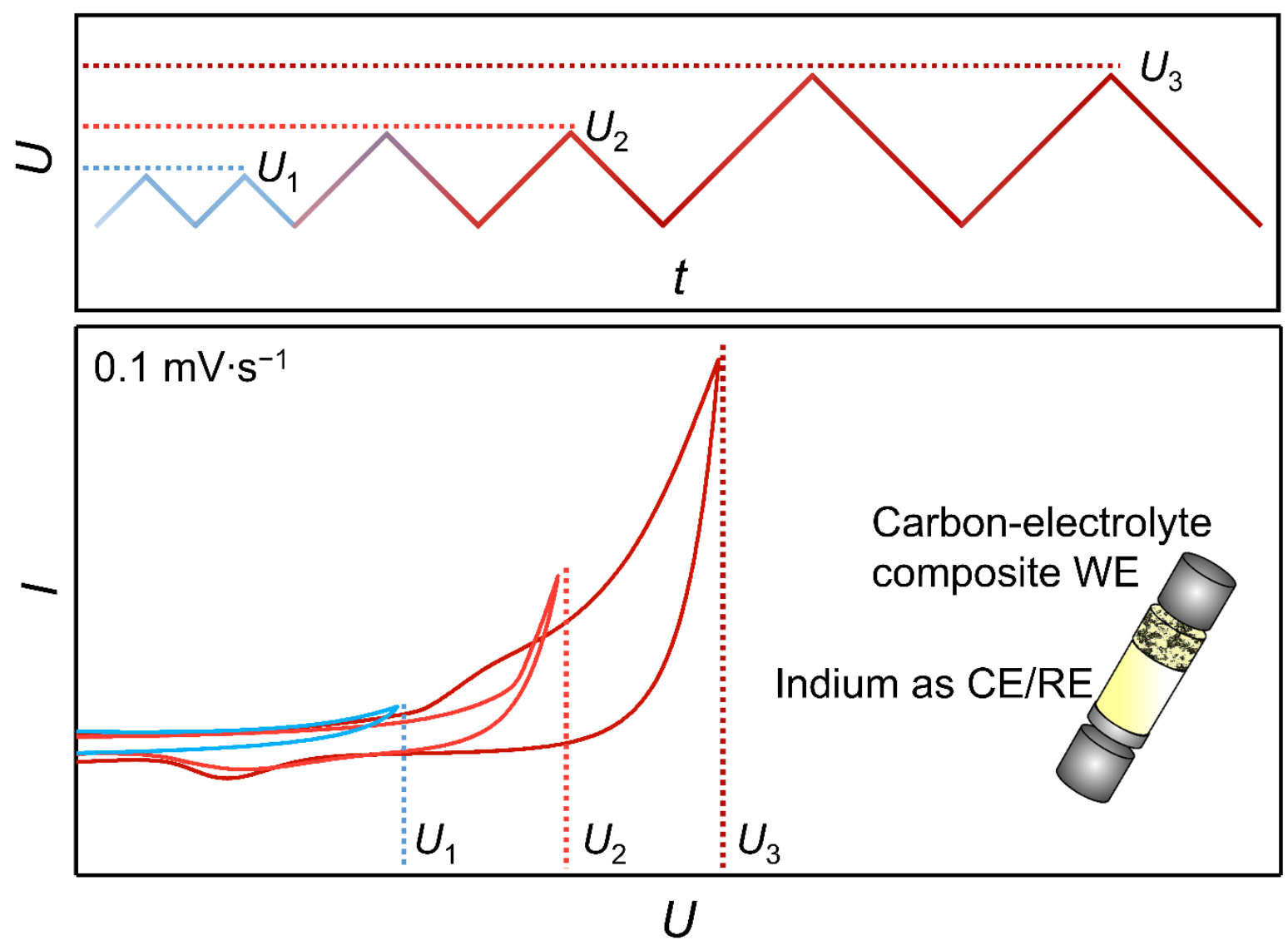

Figure S 5: Schematic of stepwise CV method. Within the experiment, two consecutive scans to each cut-off potential were conducted, followed by an increase of reversal potential for the subsequent scan $(\Delta U=0.1 \mathrm{~V})$. As described in the experimental section, a carbon-electrolyte composite was used as working electrode (WE) and indium metal as counter and reference electrode $(C E / R E)$. For better visibility, only the first scans are shown in the lower panel. 


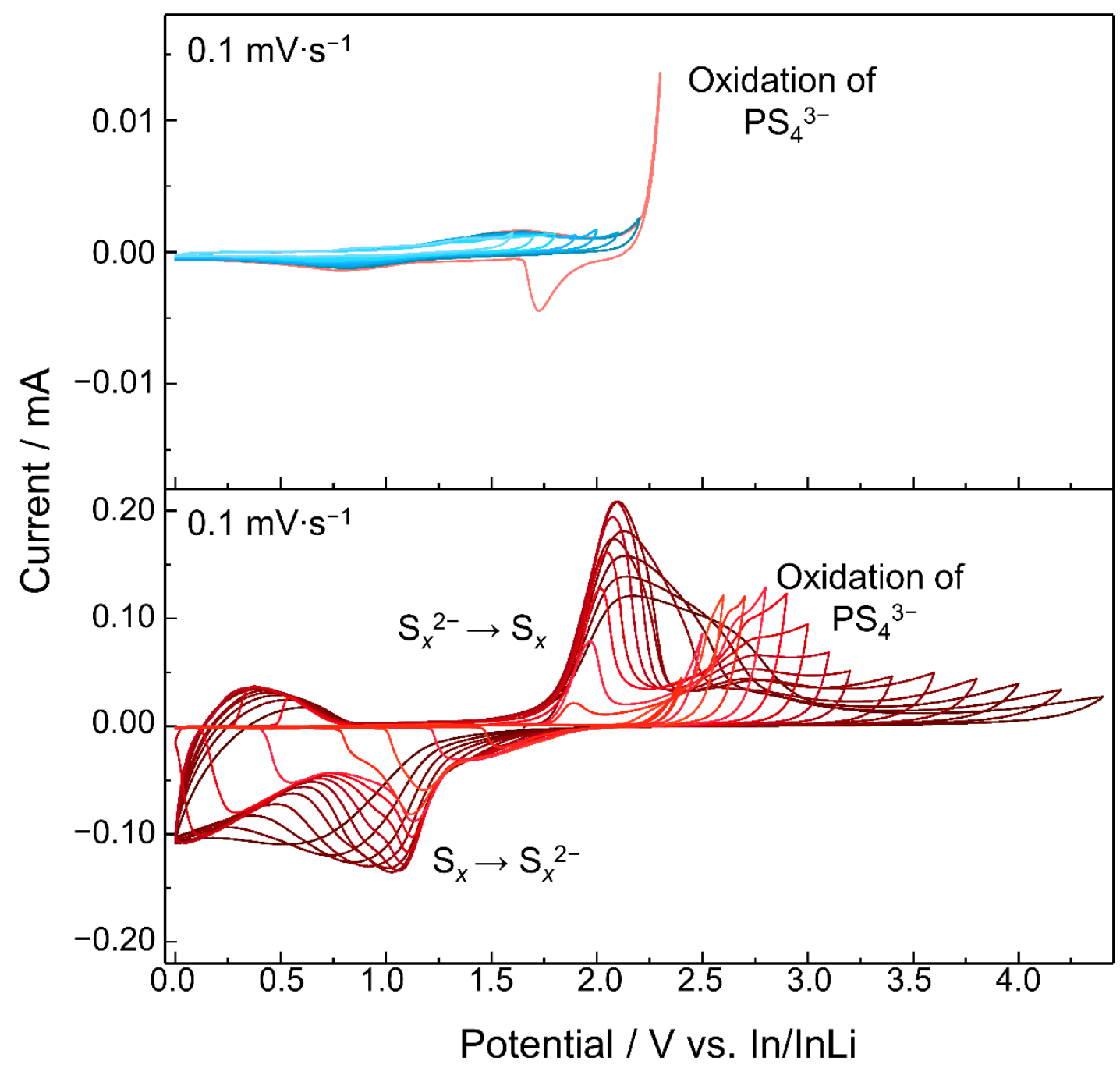

Figure S 6: Results of stepwise CV experiment on In/70:30 Li $\mathrm{L}_{2} \mathrm{~S}_{-} \mathrm{P}_{2} \mathrm{~S}_{5} / 70: 30 \mathrm{Li}_{2} \mathrm{~S}-\mathrm{P}_{2} \mathrm{~S}_{5}-\mathrm{C} 65$ (weight ratio of $S E$ to $C$ 9:1) cell. For sake of clarity, only first scans are shown. Open-circuit voltage $(O C V)$ was $0.7 \mathrm{~V}$ vs. In/InLi. Oxidative decomposition was observed for potentials exceeding $2.2 \mathrm{~V} v \mathrm{~s}$. In/InLi. The first reduction peak (peak current of $4 \mu \mathrm{A}$ ) was detected in the cathodic sweep of the scan to $2.3 \mathrm{~V}$. 


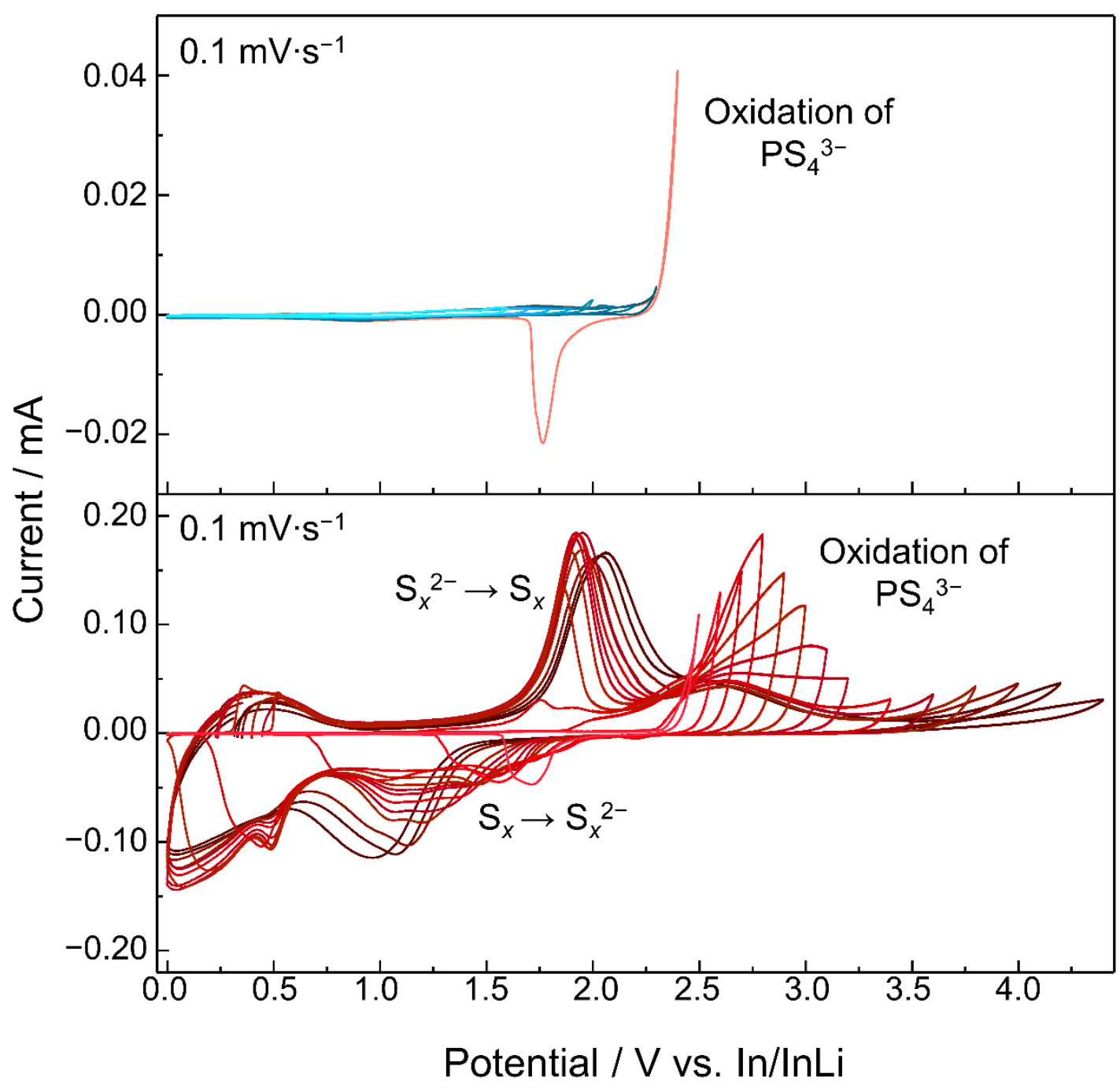

Figure S 7: Results of stepwise CV experiment on In/75:25 Li2 $\mathrm{S}_{-} \mathrm{P}_{2} \mathrm{~S}_{5} / 75: 25 \mathrm{Li}_{2} \mathrm{~S}-\mathrm{P}_{2} \mathrm{~S}_{5}-\mathrm{C} 65$ (weight ratio of SE to $C$ 9:1) cell. For sake of clarity, only first scans are shown. Open-circuit voltage $(O C V)$ was $0.6 \mathrm{~V}$ vs. In/InLi. Oxidative decomposition was observed for potentials exceeding $2.3 \mathrm{~V} v$ s. In/InLi. The first reduction peak (peak current of $21 \mu \mathrm{A}$ ) was detected in the cathodic sweep of the scan to $2.4 \mathrm{~V}$. 


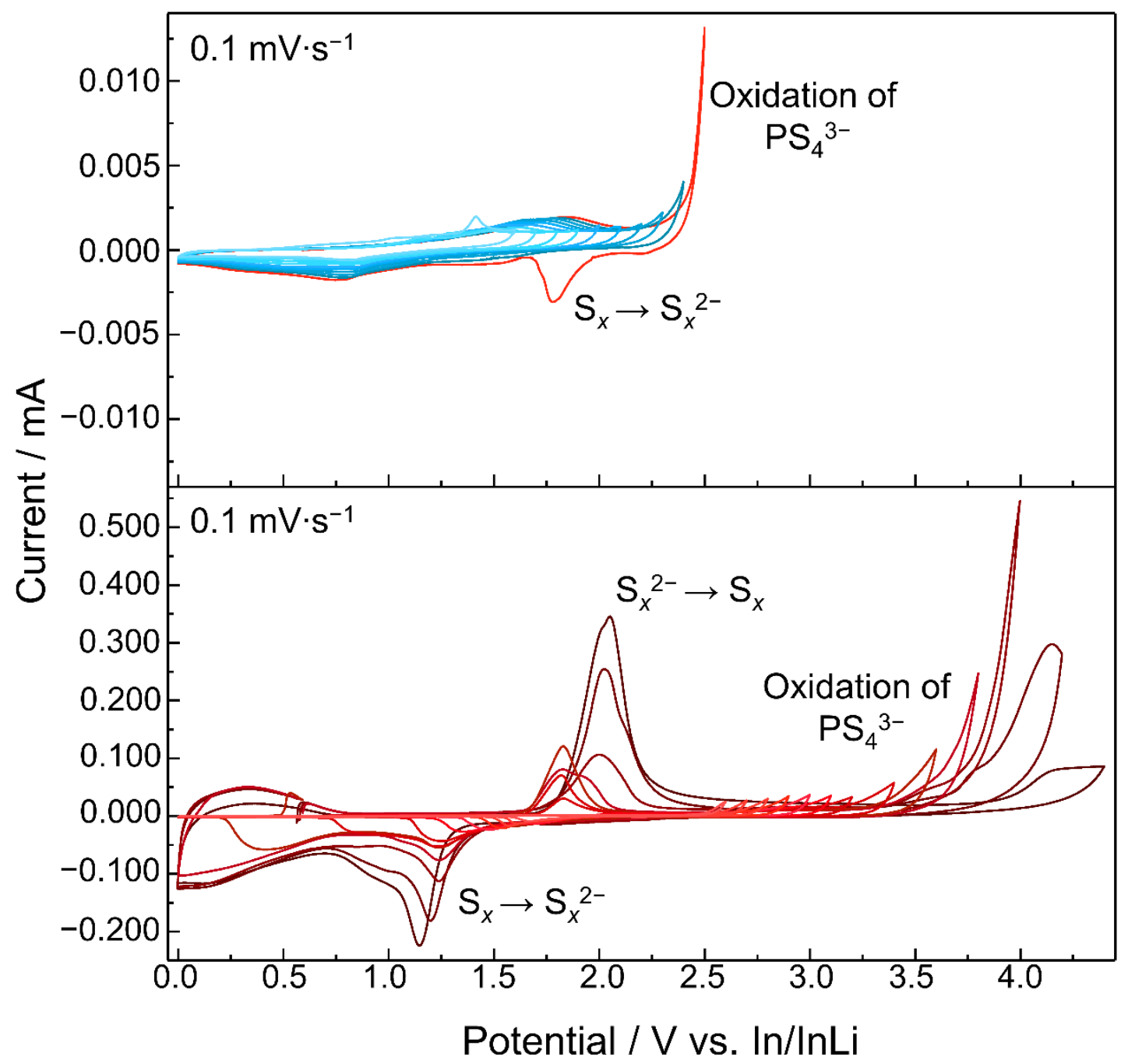

Figure S 8: Results of stepwise CV experiment on $\mathrm{In} / \mathrm{Li}_{6} \mathrm{PS}_{5} \mathrm{Cl} / \mathrm{Li}_{6} \mathrm{PS} \mathrm{S}_{5} \mathrm{Cl}-\mathrm{C} 65$ (weight ratio of SE to $C$ 9:1) cell. For sake of clarity, only first scans are shown. OCV was $0.5 \mathrm{~V} v \mathrm{v}$. In/InLi. First intensive peak was observed at $2.5 \mathrm{~V}$ (red curve in the top figure). As the first reduction peak was detected in the subsequent cathodic sweep with a peak current of $3 \mu A$, this potential is defined as the stability limit against oxidation. 


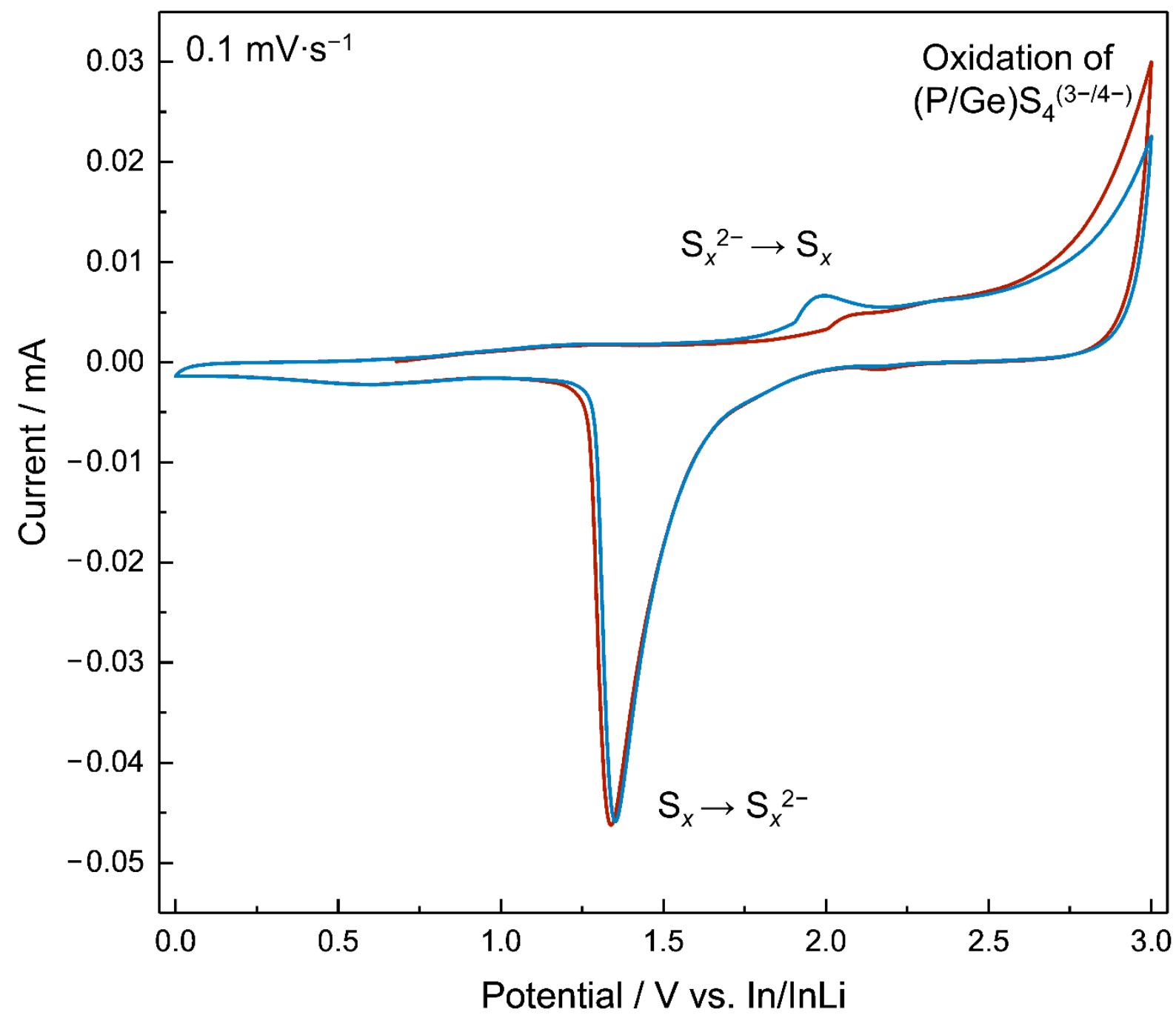

Figure S 9: Exemplary $\mathrm{CV}$ scan of $\mathrm{Li}_{10} \mathrm{GeP}_{2} \mathrm{~S}_{12}$. By repeating the potential sweep once, the decomposition can be further elucidated. The first scan (red) shows a higher maximum current at reversal potential. In the second scan (blue), the sulfur oxidation peak appears at lower potential, indicating the partially reversible oxidation of decomposition products. 


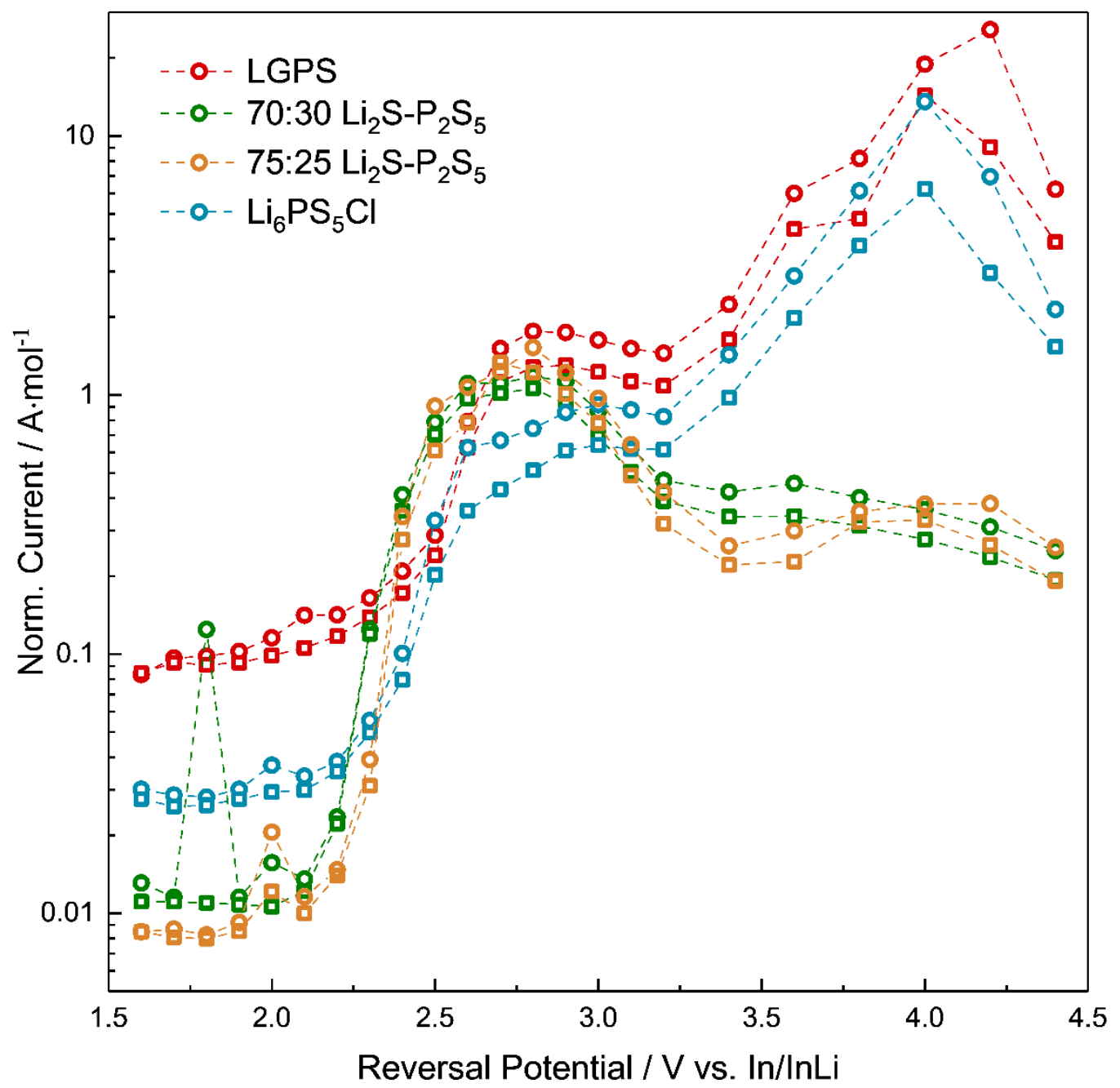

Figure S 10: Comparison of oxidative currents at reversal potentials of all conducted CV scans. The first scans (circles) show higher maximum currents compared to the subsequent potential sweep (squares). An increasing current is indicating the oxidation stability limit. 


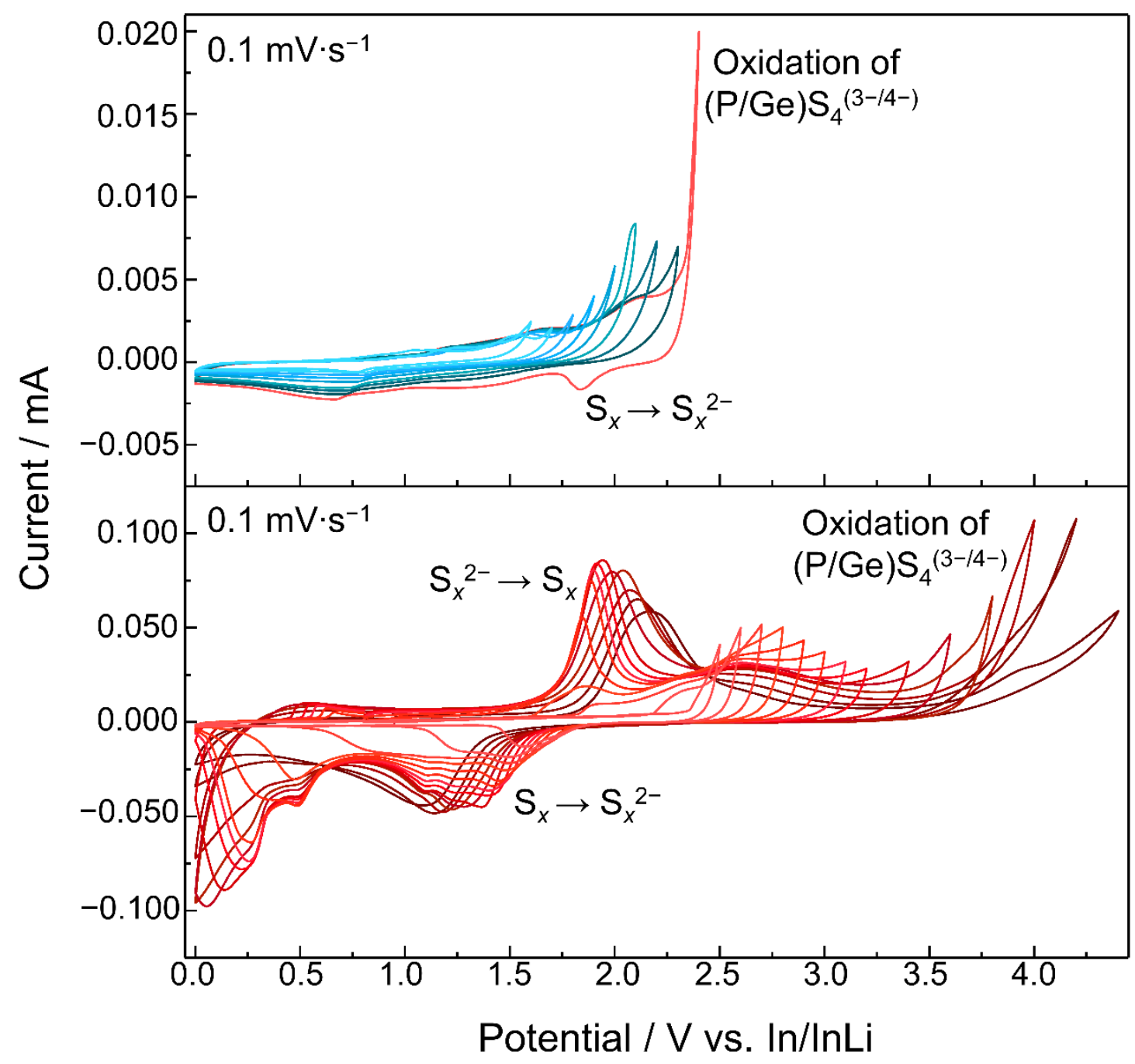

Figure S 11: Results of stepwise CV experiment on In/Li $i_{10} \mathrm{GeP}_{2} \mathrm{~S}_{12} / \mathrm{Li}_{10} \mathrm{GeP}_{2} \mathrm{~S}_{12}$ - reduced C65 cell. For sake of clarity, only first scans are shown. Open-circuit voltage (OCV) was $0.4 \mathrm{~V} v \mathrm{~s}$. In/InLi. Oxidative decomposition was observed for potentials exceeding $2.3 \mathrm{~V} v \mathrm{~s}$. In/InLi. The evolving cathodic peak at $1.8 \mathrm{~V}$ with a peak current of $2 \mu \mathrm{A}$ can be assigned to reduction of decomposition products. 


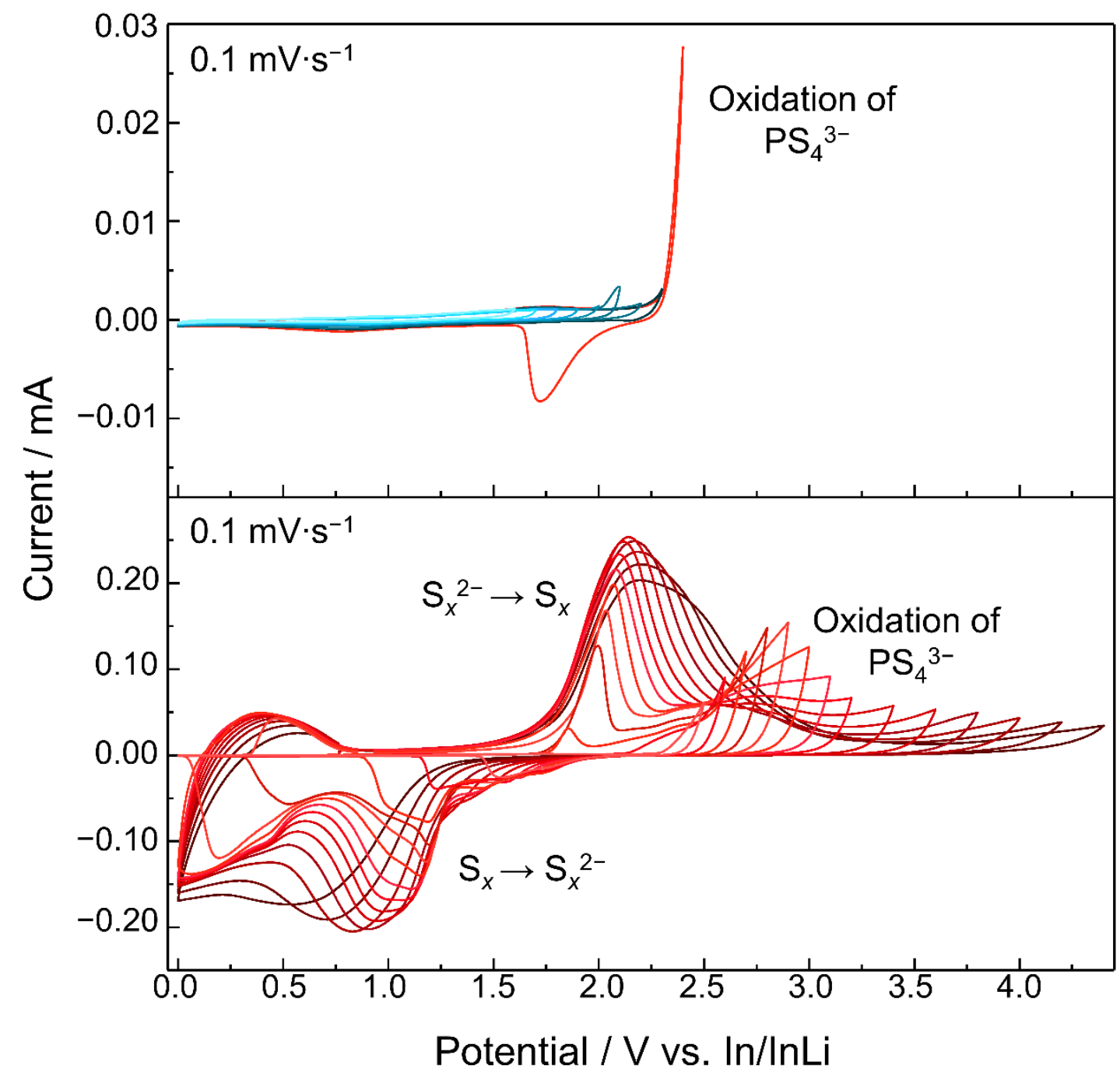

Figure S 12: Results of stepwise CV experiment on In/70:30 Li $\mathrm{i}_{2} \mathrm{~S}-\mathrm{P}_{2} \mathrm{~S}_{5} / 70: 30 \mathrm{Li}_{2} \mathrm{~S}-\mathrm{P}_{2} \mathrm{~S}_{5}$ - (reduced) C65 cell. For sake of clarity, only first scans are shown. Open-circuit voltage (OCV) was $0.6 \mathrm{Vvs.}$ In/InLi. The first distinct reduction peak was detected at $1.7 \mathrm{~V}$ with a peak current of $8 \mu \mathrm{A}$ in the scan to $2.4 \mathrm{~V}$. 


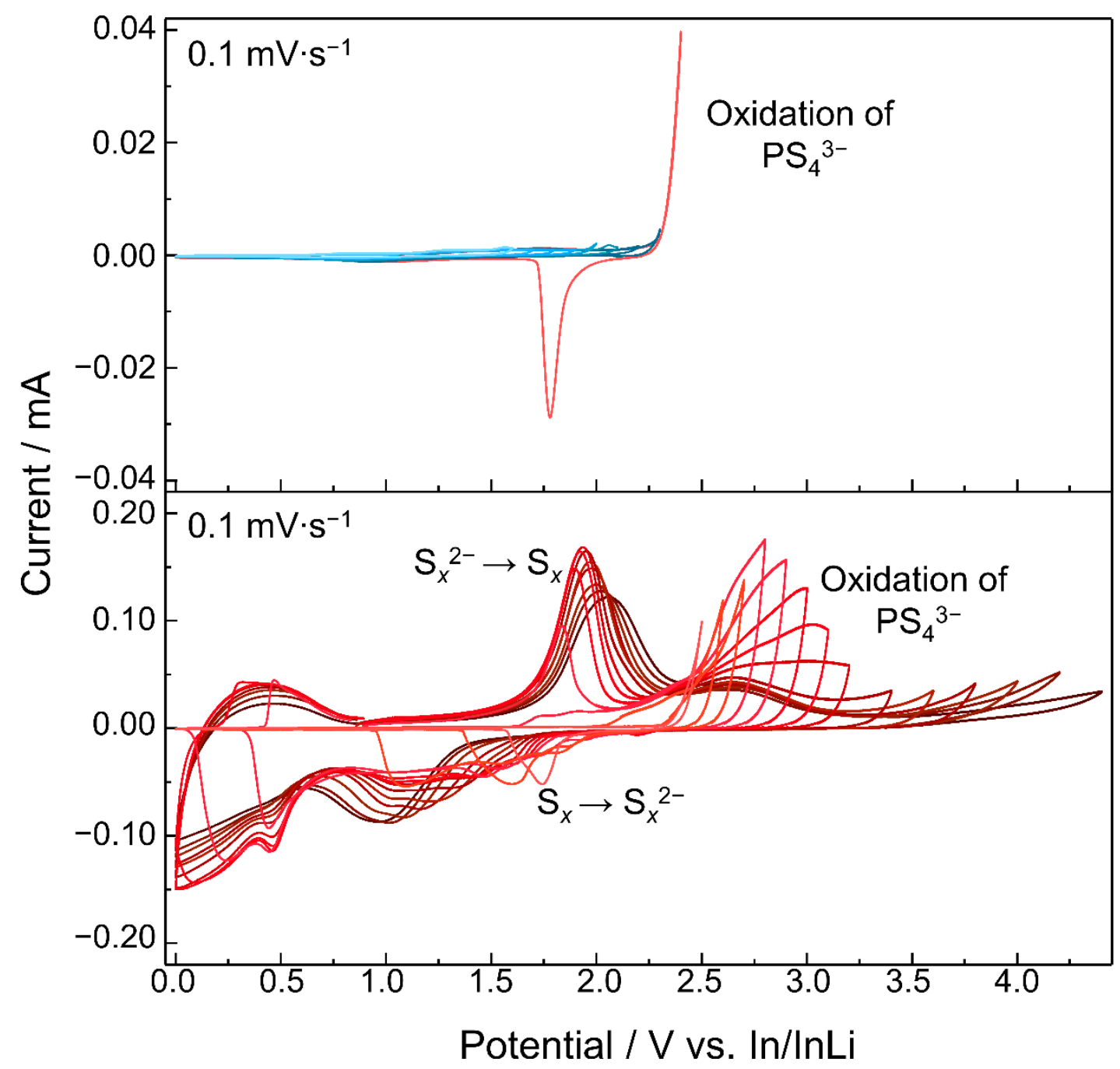

Figure S 13: Results of stepwise CV experiment on In/75:25 Li $2 S_{-} P_{2} S_{5} / 75: 25 L_{2} \mathrm{~S}_{-} \mathrm{P}_{2} \mathrm{~S}_{5}$ - (reduced) C65 cell. For sake of clarity, only first scans are shown. Open-circuit voltage (OCV) was $0.6 \mathrm{Vvs.}$ $\mathrm{In} / \mathrm{InLi}$. The first distinct reduction peak was detected at $1.8 \mathrm{~V}$ with a peak current of $28 \mu \mathrm{A}$ in the scan to $2.4 \mathrm{~V}$. 


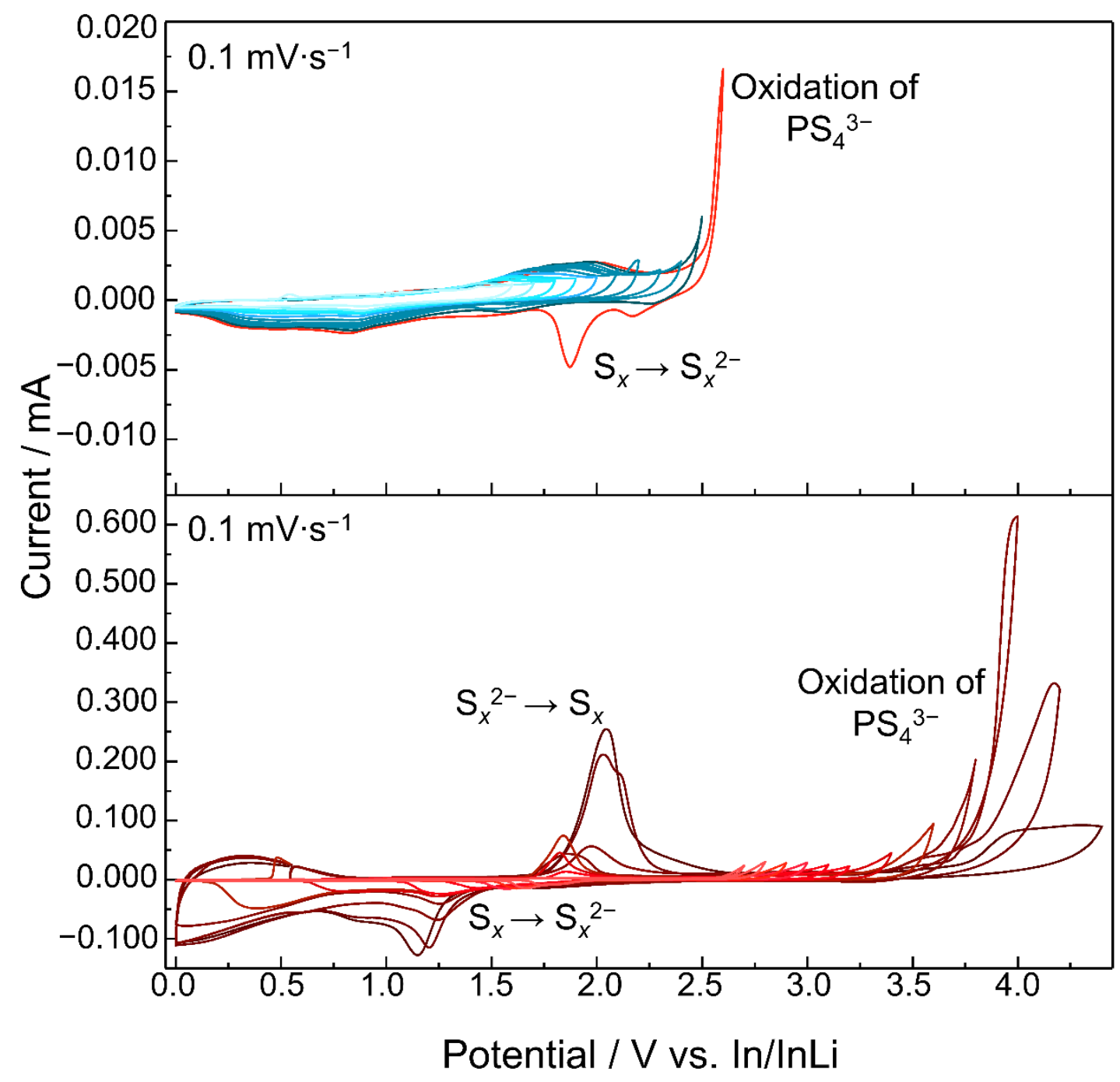

Figure S 14: Results of stepwise CV experiment on In/Li $\mathrm{CPS}_{5} \mathrm{Cl} / \mathrm{Li}_{6} \mathrm{PS} \mathrm{S}_{5} \mathrm{Cl}$-(reduced)C65 cell. For sake of clarity, only first scans are shown. OCV was $0.5 \mathrm{~V} v \mathrm{v}$. In/InLi. Oxidative decomposition was observed for potentials exceeding $2.5 \mathrm{~V} v \mathrm{~s}$. In/InLi as the first reduction peak with a peak current of $5 \mu \mathrm{A}$ was detected at $1.9 \mathrm{~V}$ in the abovementioned scan. 


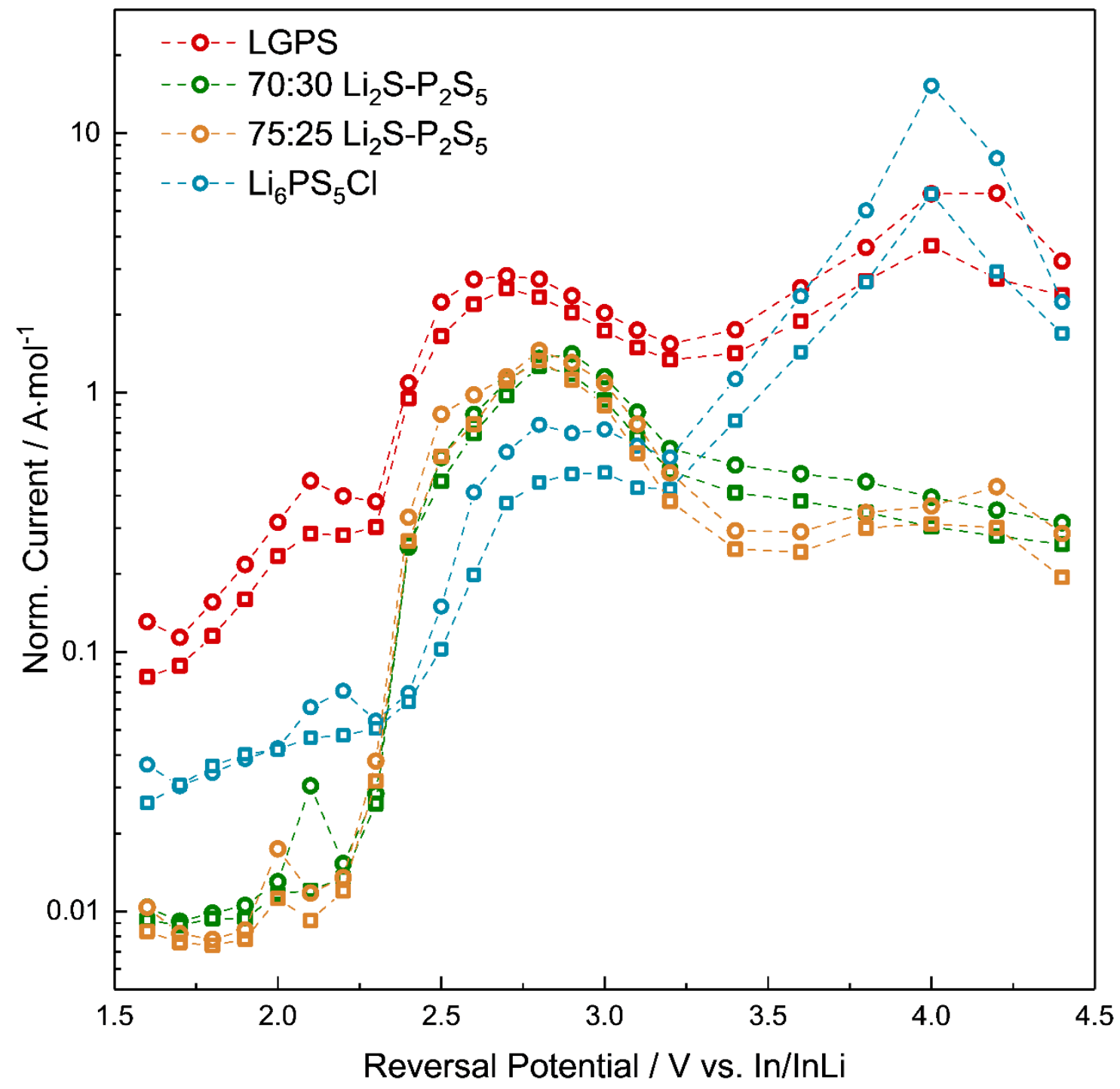

Figure S 15: Comparison of oxidative currents at reversal potentials of $C V$ scans performed on cells with reduced carbon black. Compared to vacuum-dried carbon, the onset of oxidative stability is found to be slightly shifted to higher potentials. Maximum currents of first and second scans are shown as circles and squares, respectively. 


\section{XPS Characterization}

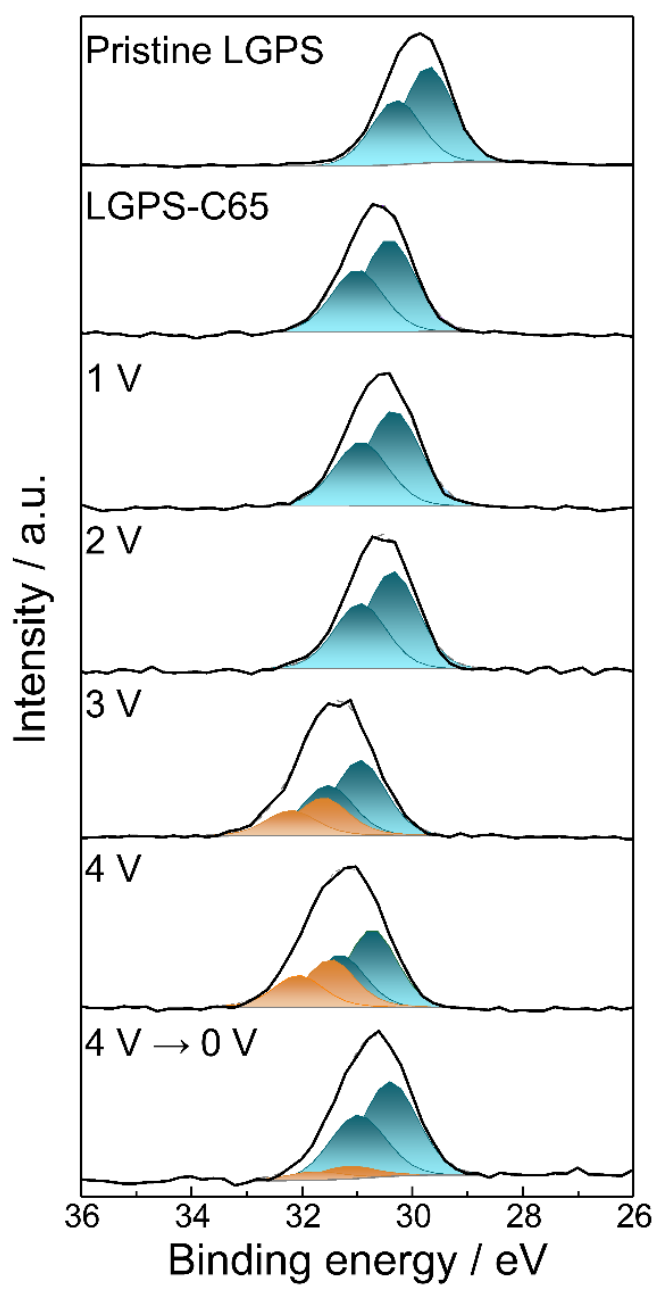

Figure S 16: XP detail spectra of Ge $3 d$ signals in $\mathrm{Li}_{10} \mathrm{GeP}_{2} \mathrm{~S}_{12}$ samples. The signal can be assigned to Ge-S bonds in $\mathrm{GeS}_{4}{ }^{4-}$. Treatment at potentials $>2 \mathrm{~V}$ leads to a shift to higher binding energies. After treatment at $3 \mathrm{~V}$, an additional species starts to evolve at higher binding energies which can be attributed to oxidation products containing Ge-S-Ge bonds (orange).. 


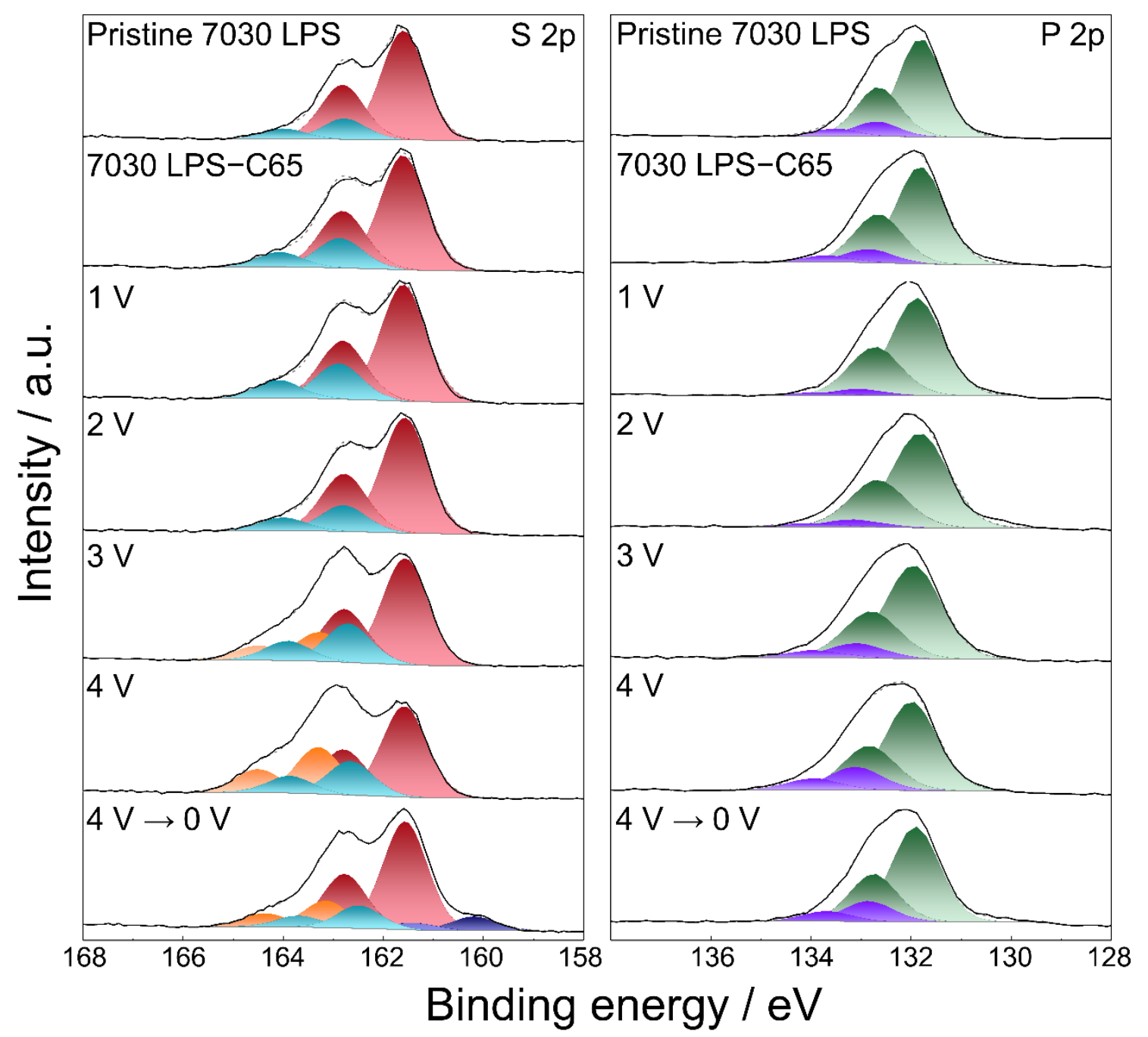

Figure S 17: XPS characterization of 70:30 $\mathrm{Li}_{2} \mathrm{~S}_{-} \mathrm{P}_{2} \mathrm{~S}_{5}$-C composite treated at different potentials. Shown are $S 2 p$ and $P 2 p$ signals. Orange doublet in $S 2 p$ is attributable to elemental sulfur, which is in good agreement with the stepwise $C V$. As shown in $4 \mathrm{~V} \rightarrow 0 \mathrm{~V}$ spectrum, $S$ is reduced to $\mathrm{Li}_{2} S$ (dark purple in $S 2 p$ ). Interestingly, the light blue peaks in $S 2 p$, corresponding to the $P-S-P$ bonds, are still present after reduction of the sample, which also shows in the oxidized species in $P 2 p$ spectra (purple peaks). 


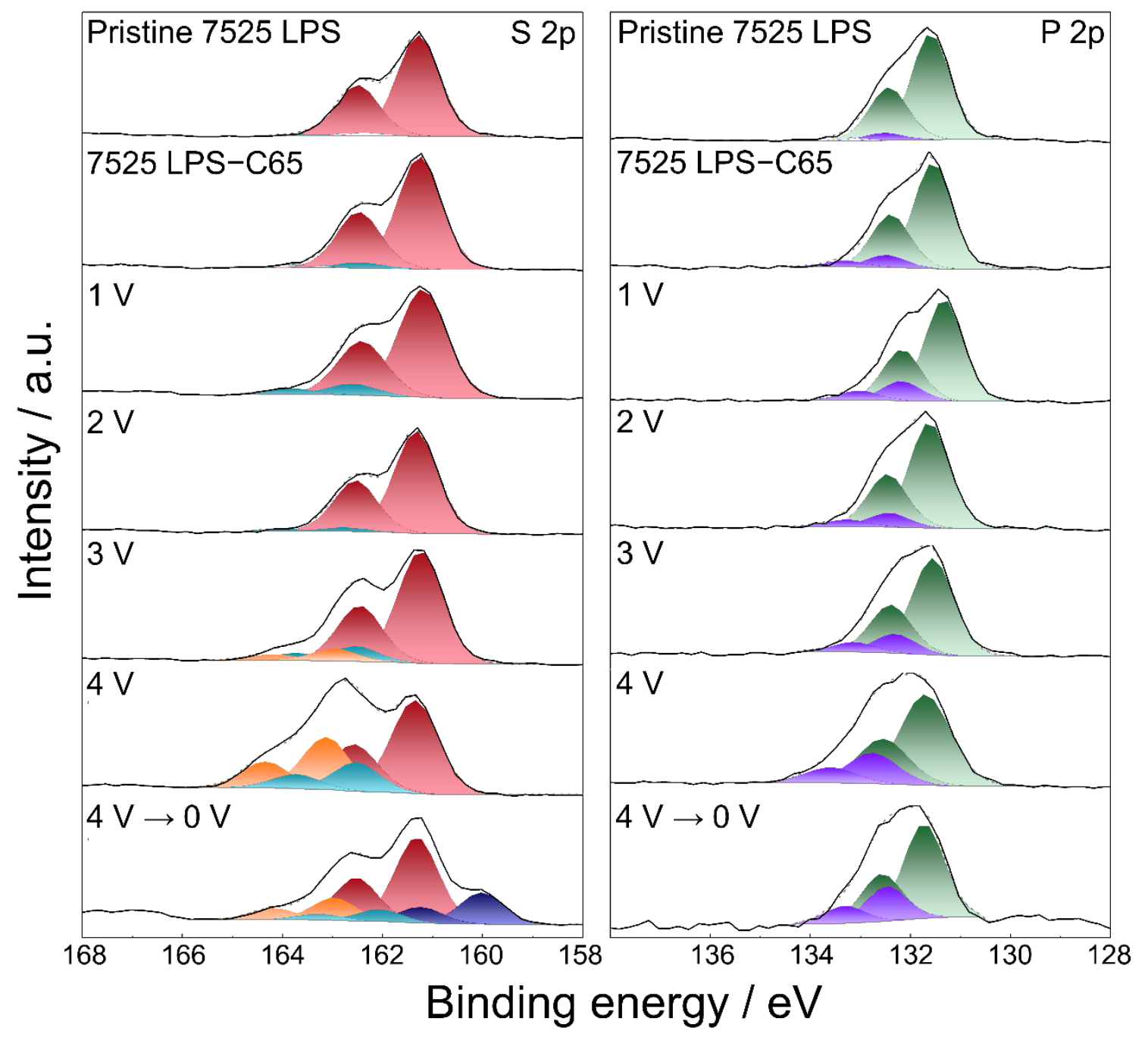

Figure S 18: XPS characterization of 75:25 $\mathrm{Li}_{2} \mathrm{~S}_{-} \mathrm{P}_{2} \mathrm{~S}_{5}$-C composite treated at different potentials. Shown are $S 2 p$ and $P 2 p$ signals. The color assignment corresponds to the previous figure $S 17$. Results are in good agreement with stepwise $C V$. 


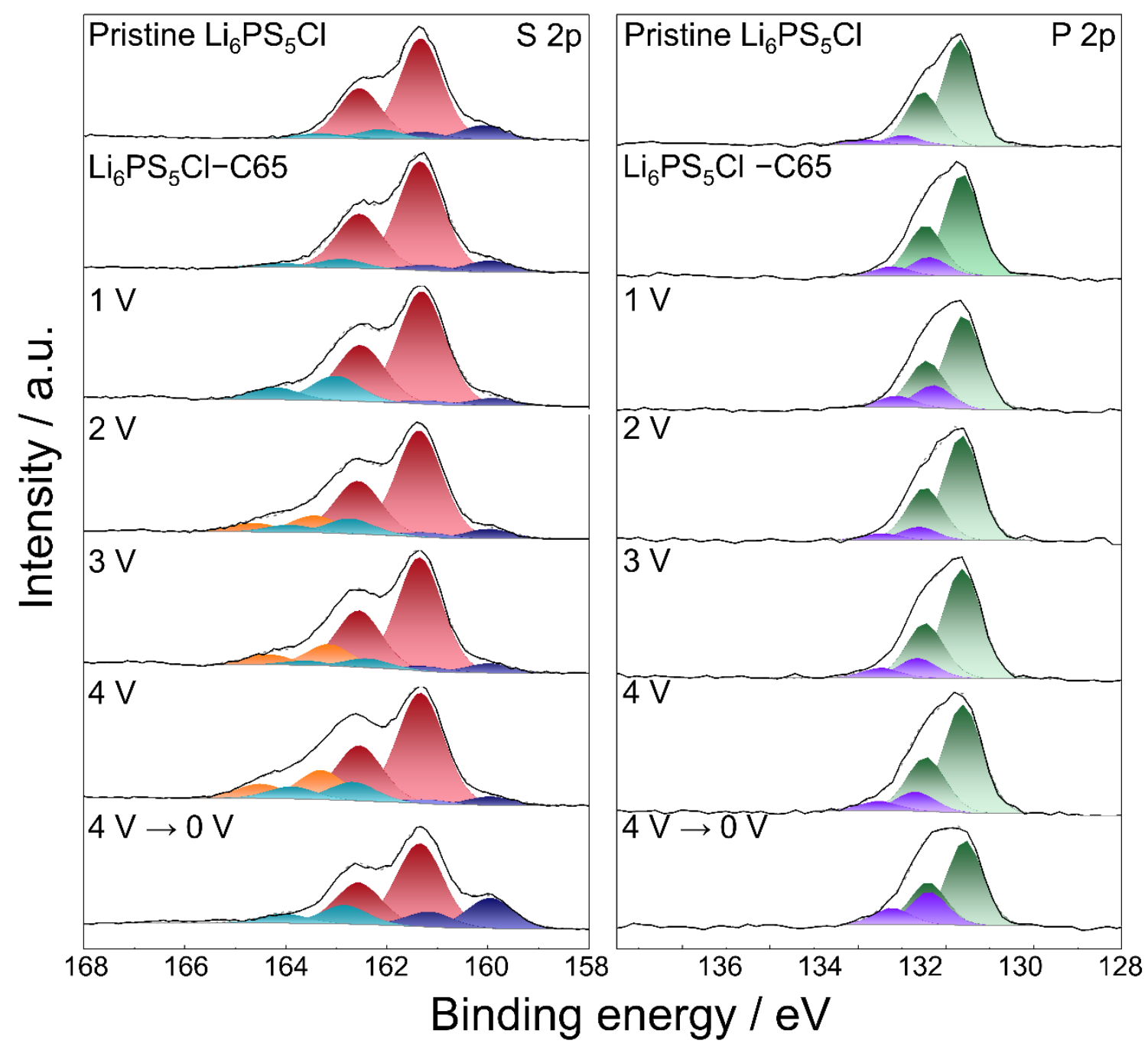

Figure S 19: XPS characterization of $\mathrm{Li}_{6} \mathrm{PS}_{5} \mathrm{Cl}$-C composite treated at different potentials. Shown are $S 2 p$ and $P 2 p$ signals. The color scheme is identical with Figure $S$ 17. Remarkably, no reduced phosphorus species could be identified after treatment at $0 \mathrm{~V} v \mathrm{~s}$. In/InLi. 


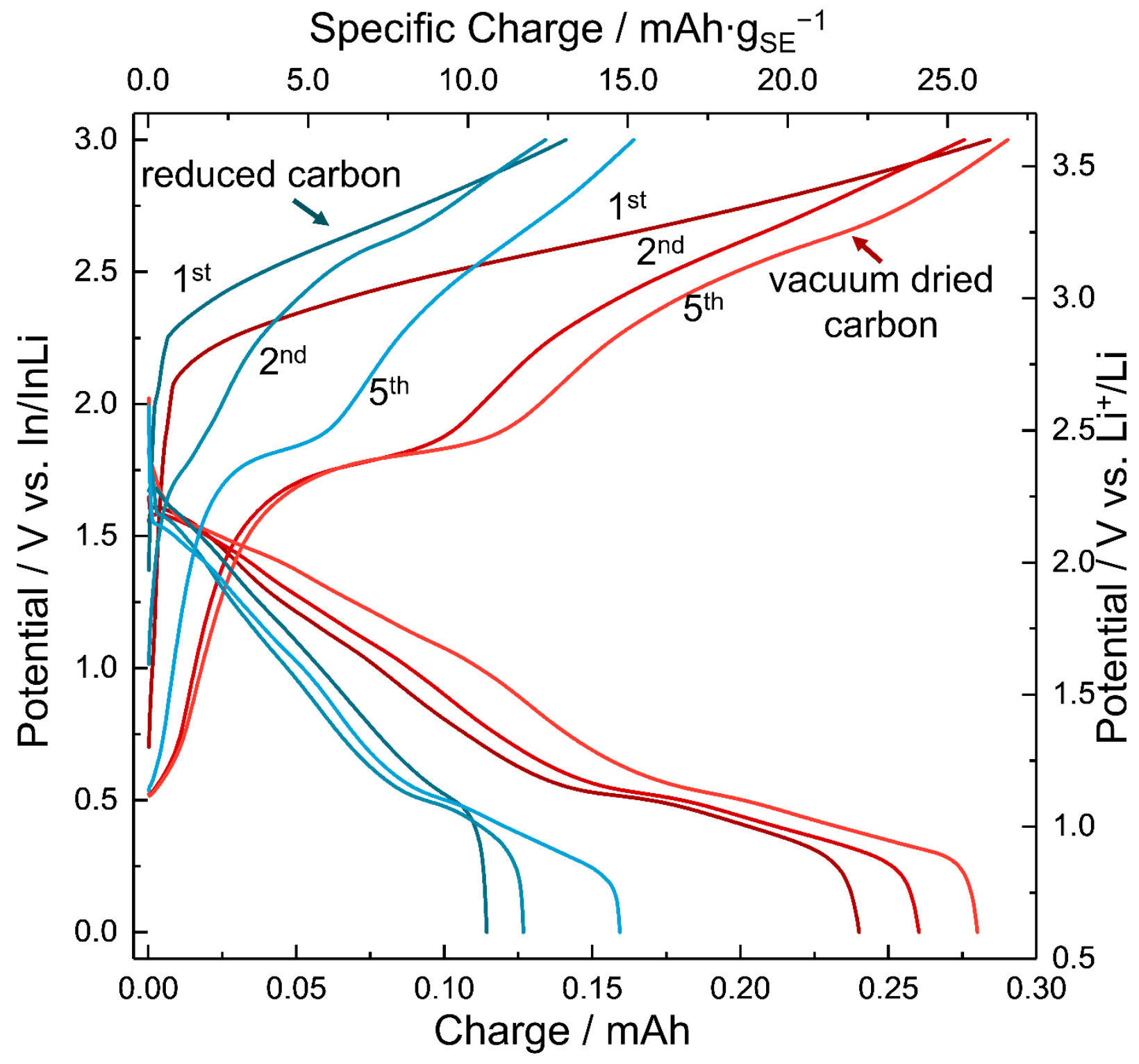

Figure S 20: Influence of carbon surface treatment on charge-discharge curves for In/Li $i_{10} \mathrm{GeP}_{2} \mathrm{~S}_{12}{ }^{\prime} \mathrm{C} 65$ cells. Reduced C65 (blue) leads to lower capacitances compared to vacuum dried carbon (red). However, as the general characteristics remain unchanged, variations mostly show in the overpotential. 


\section{S18: Estimation of spatial extension of reaction layer.}

For a rough estimation of the thickness of the reaction layer at the electrolyte/carbon interface, a charge $Q$ of $0.28 \mathrm{mAh}$ (obtained in first "charge", see Fig. 4) is assumed as Faradaic charge for the oxidation of $\mathrm{Li}_{10} \mathrm{GeP}_{2} \mathrm{~S}_{12}$. Based on Eq. 1 , the molar amount $n$ of oxidized $(\mathrm{P} / \mathrm{Ge}) \mathrm{S}_{4}{ }^{\left(3^{-/ 4-}\right)}$ can be calculated to be:

$$
n\left(\mathrm{P} / \mathrm{Ge}^{(3-/ 4-)}\right)=\frac{Q}{\mathrm{~F}}=1.04 \cdot 10^{-5} \mathrm{~mol}
$$

As the next step, changes in crystal structure are neglected and thereby a constant volume of the unit cell $\left(V_{\text {cell }}=9.56 \cdot 10^{-28} \mathrm{~m}^{3}\right)$ is assumed. For complete conversion according to Eq. 1 of 6 tetrahedrons per unit cell, the volume $V$ of the reaction layer can be estimated to be:

$$
V=\frac{n\left(\mathrm{P} / \mathrm{Ge}^{(3-/ 4-)}\right) \cdot N_{\mathrm{A}} \cdot V_{\text {cell }}}{6}=9.98 \cdot 10^{-10} \mathrm{~m}^{3}
$$

The theoretical surface of the working electrode $A_{\mathrm{WE}}$ can be calculated based on the employed mass and specific BET surface of employed carbon black:

$$
A_{\mathrm{WE}}=62 \frac{\mathrm{m}^{2}}{\mathrm{~g}} \cdot 1.2 \mathrm{mg}=0.074 \mathrm{~m}^{2}
$$

Finally, assuming a homogeneous layer at the SE/carbon interface, the thickness $d$ of the reaction layer can be estimated:

$$
d=\frac{V}{A_{\mathrm{WE}}}=13 \mathrm{~nm}
$$

However, as the decomposition will most likely result in the formation of amorphous phases and the carbon surface represents an upper limit for interphase formation, this calculation has to be seen only as a rough estimate.

\section{References}

(S1) Weber, D. A.; Senyshyn, A.; Weldert, K. S.; Wenzel, S.; Zhang, W.; Kaiser, R.; Berendts, S.; Janek, J.; Zeier, W. G. Structural Insights and 3D Diffusion Pathways within the Lithium Superionic Conductor $\mathrm{Li}_{10} \mathrm{GeP}_{2} \mathrm{~S}_{12}$. Chem. Mater. 2016, 28, 5905-5915.

(S2) Kraft, M. A.; Culver, S. P.; Calderon, M.; Böcher, F.; Krauskopf, T.; Senyshyn, A.; Dietrich, C.; Zevalkink, A.; Janek, J.; Zeier, W. G. Influence of Lattice Polarizability on the Ionic Conductivity in the Lithium Superionic Argyrodites $\mathrm{Li}_{6} \mathrm{PS}_{5} \mathrm{X}(\mathrm{X}=\mathrm{Cl}, \mathrm{Br}, \mathrm{I}) . J$. Am. Chem. Soc. 2017, 139, 10909-10918. 